\title{
Controversias sobre vulnerabilidad ante el riesgo minero en el río Sonora, México
}

\section{Controversies to Mining Risk in the Sonora River, Mexico}

\author{
Yuriria Orozco Martínez* (1) https://orcid.org/0000-0002-7654-3525 \\ Liz lleana Rodríguez Gámez ${ }^{* *}$ (1) https://orcid.org/0000-0002-4684-9531
}

\section{Resumen}

El objetivo de la investigación es analizar, desde varios puntos de vista, la percepción acerca de las vulnerabilidades debidas a la minería, considerando las posturas de diferentes actores (autoridades, activistas, asociaciones civiles, organizaciones sociales, académicos y pobladores) ante el riesgo minero en el río Sonora, México. Se emplea una metodología cualitativa que analiza los discursos de expertos y pobladores recolectados a través de entrevistas, así como de un taller de cartografía social con activistas locales. Los resultados muestran controversias entre los actores sobre la vulnerabilidad política, social, económica, física, técnica y ambiental; también indiferencias y similitudes en las posturas en torno a vulnerabilidad ideológico-cultural. La evaluación de los riesgos tecnológicos es con frecuencia politizada, porque involucra muchos intereses y valores. Por eso aquí se propone que en estos debates se asegure la participación tanto de los expertos como de los pobladores afectados. Una de las limitaciones de esta investigación es que el perfil de expertos seleccionado no incluyó al de los científicos, sino sólo a quienes Funtowicz y Ravetz llaman expertos de consultoría profesional.

Palabras clave: análisis del discurso; minería; percepción; riesgo; vulnerabilidad; río Sonora.

\begin{abstract}
The objective of this research is to carry out an analysis of the perception of vulnerabilities from multiple points of view, considering the positions expressed by different actors (e.g. authorities, activists, civil associations, social organizations, scholars, and people) about mining risk in Sonora River, Mexico. A qualitative methodology is used to examine the experts and people's discourse, collected through interviews and from a social mapping workshop with local activists. The results show controversies among the actors, related to political, social, economic, physical, technical, and environmental vulnerabilities, as well as indifferences and similarities on ideological and cultural vulnerabilities. Technological risks assessment is frequently politicized, since it involves many interests and values; therefore, the proposal here is that the participation of both, experts and people concerned, must be ensured in these discussions. One of this research limitation is that the selected experts profile did not include scientists, but those who Funtowicz and Ravetz call professional consultancy experts.

Keywords: risk; perception; vulnerability; mining; Sonora River; discourse analysis.
\end{abstract}

Cómo citar: Orozco Martínez,Y., y Rodríguez Gámez, L. I. (2020). Controversias sobre vulnerabilidad ante el riesgo minero en el río Sonora, México. región y sociedad, 32, el 319. doi: I0.22198/rys2020/32/1319

* Autora para correspondencia. El Colegio de Sonora. Ave. Álvaro Obregón Núm. 54, Col. Centro, C. P. 83000. Hermosillo, Sonora, México. Correo electrónico: yorozco@colson.edu.mx

${ }^{* *}$ El Colegio de Sonora, Centro de Estudios del Desarrollo. Ave. Álvaro Obregón Núm. 54, Col. Centro, C. P. 83000. Hermosillo, Sonora, México. Correo electrónico: Irodriguez@colson.edu.mx

Recibido: 11 de marzo de 2020

Reevaluado: 19 de octubre de 2020

Aceptado: 10 de noviembre de 2020

Liberado: 9 de diciembre de 2020 


\section{Introducción}

La amenaza y la vulnerabilidad representan una dupla inseparable en los análisis de riesgos. Dichos análisis se realizan a partir de dos enfoques conceptuales contrapuestos: 1) el objetivo, también llamado positivismo ingenuo o enfoque técnico, y 2) el subjetivo, denominado relativismo cultural o enfoque sociológico (López y Luján, 2000; Shrader-Frechette, 1991; Sjöberg y Drotzz-Sjöberg, 1994). El primer enfoque sostiene que las estimaciones de riesgo son objetivas y neutrales; por tanto, excluye todo tipo de valores y componentes éticos, y considera la ciencia la vía óptima para acceder a la realidad natural y social (Ortega, 2014; Shrader-Frechette, 1991). El segundo enfoque reconoce que el riesgo es una construcción de la sociedad, cuyas creencias y valores compartidos por determinados grupos sociales y culturales influyen en la manera de considerar qué es y qué no es riesgo (Douglas y Wildavsky, 1982).

Para tal efecto, cuando está presente un riesgo tecnológico, se dan controversias entre al menos dos grupos. Por un lado, para algunos expertos y representantes de la industria -quienes suelen manejar la idea de la "ciencia" como proveedora de saberes específicos que certifican la seguridad y el manejo de los efectos de la tecnología-, las evaluaciones subjetivas de las comunidades son infundadas, argumentando que si los pobladores entendiesen más sobre estadística no estarían tan preocupados por los riesgos de determinada tecnología. Por otro lado, se encuentran los legos, ${ }^{1}$ quienes, al ser potencialmente afectados, elaboran ponderaciones de las posibles consecuencias de un accidente, basándose en sus experiencias cotidianas, en sus acervos tradicionales y en información de lo que sucede en otros sitios (Gudynas, 2018; Ortega, 2014).

De ahí la importancia de conocer las percepciones que los diferentes actores involucrados elaboran en relación con el riesgo. El objetivo es explicar la imagen que éstos construyen, así como las problemáticas o conflictividades, sobre el espacio o territorio en que se desenvuelven (Ferrari, 2011). En otras palabras, abordar la percepción del riesgo supone el análisis de las creencias, actitudes, juicios y sentimientos, así como los valores y disposiciones sociales que los grupos adoptan ante la peligrosidad del fenómeno y las condiciones de vulnerabilidad (Ferrari, 2017). Para comprender el proceso de construcción social en situaciones de riesgo, se analiza el caso de la región del río Sonora, al noroeste de México, en donde ocurrió, el 6 de agosto de 2014, un derrame de 40 mil metros cúbicos de sulfato de cobre acidulado en el sistema hídrico de la cuenca alta del río Sonora (véase figura 1).

El accidente, calificado como el mayor desastre en la historia ambiental del país (Secretaría de Medio Ambiente y Recursos Naturales [SEMARNAT], 2015), contaminó al menos cuatro cuerpos de agua -el arroyo Tinajas, los ríos Bacanuchi y Sonora y la presa Ing. Rodolfo Félix Valdés “El Molinito” (Alfie, 2015;

1 En este caso son activistas y pobladores cuyos conocimientos y valores, distintos de los sistemas expertos, se obtienen a partir de la observación y las vivencias de diferentes eventos que amenazan la vida y que pueden destruir el entorno. Una de sus principales características es que son prácticos e indispensables para el comportamiento diario y la protección de vidas (Gálvez, 2015). Así mismo marcan la percepción, "definida por sistemas culturales y sociales integrados por las creencias sobre diferentes aspectos del mundo, los valores y las formas, según la cual los miembros pertenecientes a una sociedad abordan el conocimiento del mundo" (Castrillón, Martínez, Puentes, Sánchez y Tocancipa, 2015, p. 17). 
Toscana y Hernández, 2017) - y ocasionó daños ambientales, económicos y a la salud (Ibarra y Moreno, 2017; Luque, Murphy, Jones, Búrquez, Martínez, Manrique y Esquer, 2019). El derrame fue producto de una falla de tubería en una presa de relaves (presa de jales) de la empresa minera Buenavista del Cobre, S. A. de C.V. (subsidiaria de Grupo México), localizada en el municipio de Cananea, y afectó río abajo a los municipios de Arizpe, Banámichi, Huépac, San Felipe de Jesús, Aconchi, Baviácora y Ures (véase figura 1), región donde habitaban en 2015 poco más de 22 mil personas (Instituto Nacional de Estadística y Geografía [INEGI], 2016a).

Figura 1. Localización de la zona de municipios afectados por el derrame de lixiviados de cobre el 6 de agosto de 2014 en el río Sonora

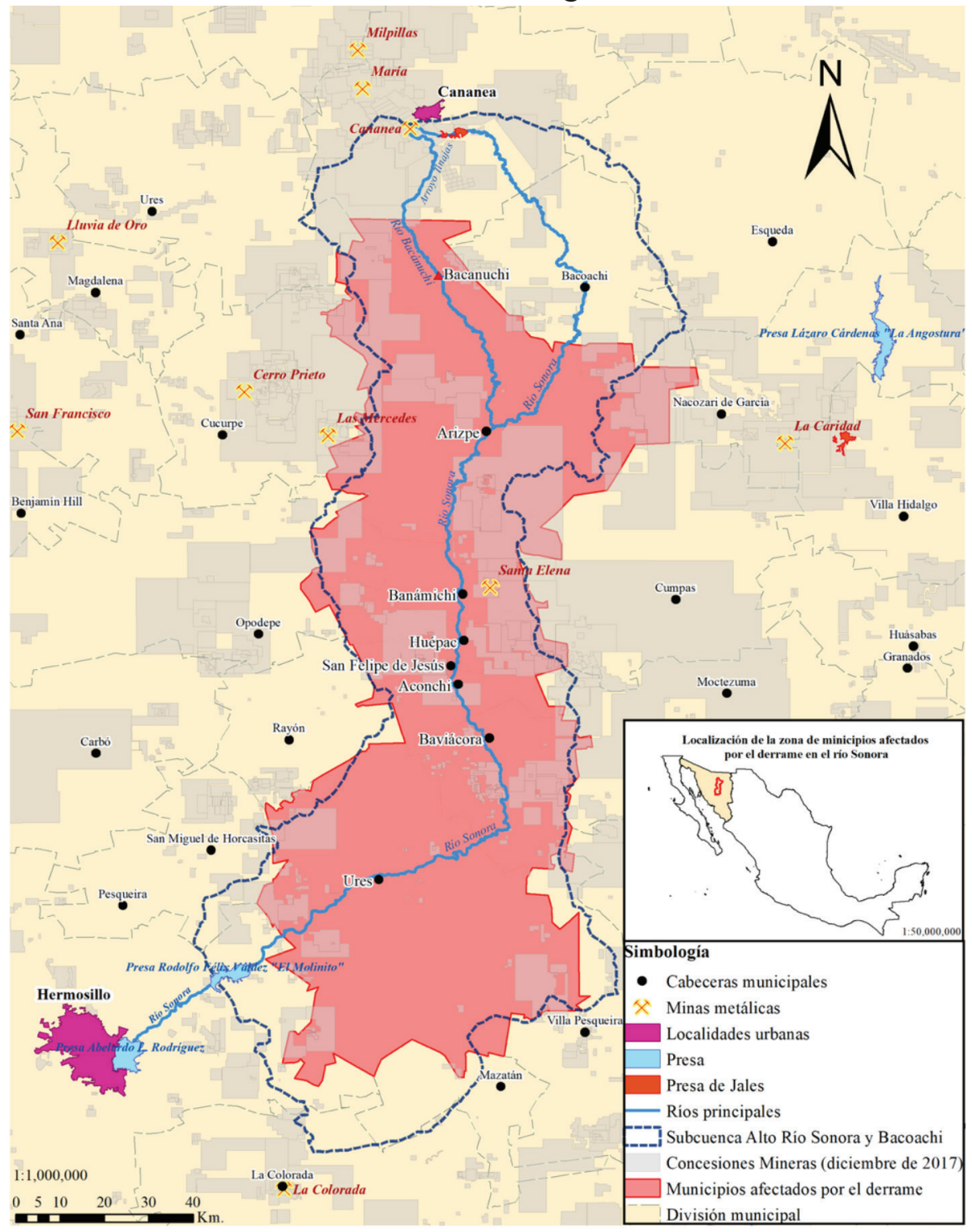

Fuente: elaboración propia con información del INEGI (2016b) y de la Secretaría de Economía (SE) (2015b). 
La región se encuentra en una zona rica en minerales, en donde operan dos minas metálicas - Buenavista en Cananea (cobre) y Santa Elena (oro y plata) en Banámichi (véase figura 1)-, así como proyectos de exploración avanzada en las minas Las Chispas (oro y plata) y El Gachi (oro y plata) en Arizpe, y La Ventana (zinc, plomo y plata) en San Felipe de Jesús (Servicio Geológico Mexicano [SGM], 2018). Además, están registradas 299 concesiones mineras en la región (SE, 2015a). También se encuentran, aunque inactivas, las siguientes plantas: la mina de zinc, plomo y plata San Felipe en San Felipe de Jesús; la mina de wolframio (tungsteno) El Jaralito en Baviácora; y la mina de oro y plata Tetuachi en Arizpe (SGM, 2018).

La actividad minera es una fuente de amenazas que involucran, por ejemplo, fallos en las tuberías y presas de relaves, derrames de sustancias, botaderos de desechos, desprendimientos de rocas y derrumbes, transportación hacia y desde el yacimiento, hundimientos, incendios y explosiones, así como minas abandonadas (Programa de Naciones Unidas para el Medio Ambiente [PNUMA], 2004). Estos problemas ocasionan a su vez accidentes, pérdidas y lesiones de vidas humanas, daños a la propiedad dentro de las instalaciones o fuera de ellas y trastornos sociales, económicos y ambientales. En consecuencia, la magnitud de las posibles pérdidas o impactos perjudiciales serán producto de la interacción entre tales amenazas y las condiciones de vulnerabilidad (Wilches-Chaux, 1993, 1998).

La presencia de la actividad minera en la región del río Sonora constituye una amenaza latente que puede materializarse, en cualquier momento, en otro evento o accidente que ocasione daños severos al entorno y a las comunidades expuestas. Es quizás debido a esto que, a cinco años del desastre socio-económico-ambiental en el río Sonora, éste sigue llamando la atención de los medios de comunicación, de la opinión pública y de los estudiosos. Se manifiestan dos perspectivas contradictorias en sendos grupos, conformados, por un lado, por quienes todavía cuestionan el impacto económico, social y ambiental del derrame, así como las deficiencias, según Albert y Jacott (2015), y la manera en que la empresa minera y los diferentes órganos del gobierno enfrentaron la emergencia; $y$, por otro lado, por quienes aseguran que ya no existen tales impactos en el río Sonora y señalan que "inclusive hay progreso y la industria minera beneficia a las comunidades con empleos dignos y bien remunerados, cuida el ambiente, provoca arraigo en los jóvenes y desarrolla obras de infraestructura" (Gutiérrez, 2019).

El suceso ocasionó, en su momento, una crisis socioambiental y económica en la región. También evidenció las amenazas y las vulnerabilidades de la población frente a la actividad minera, las cuales, con el paso del tiempo, se han ido (re)construyendo. Por consiguiente, al realizar un análisis de riesgo en la región, se hace necesario llevar a cabo una observación alejada de las visiones "extremas" de suponer que los expertos están libres de valores y que el relativismo cultural no es objetivo en ningún aspecto. Como bien señala Ortega (2014), "las evaluaciones deben realizarse en un contexto democrático, donde se puedan comparar diversos análisis, contrastarlos y enmendarlos. Se debe 
asegurar que en dichos debates participen tanto los expertos como los legos potencialmente afectados" (p. 40).

De ahí que el presente artículo tenga como objetivo realizar un análisis de la percepción de las vulnerabilidades (desde varias dimensiones), considerando los discursos expresados por diferentes actores (autoridades, activistas, asociaciones civiles, organizaciones sociales, académicos y pobladores) en torno al riesgo minero en el río Sonora. En primer lugar, se delinea el marco teórico y conceptual del riesgo, la amenaza y la vulnerabilidad, así como el desarrollo de los dos enfoques conceptuales involucrados en los análisis de riesgos: el objetivo y el subjetivo. En segundo lugar, se expone la estrategia metodológica de la investigación, la cual se enfoca en dos herramientas: la aplicación de entrevistas abiertas y la realización de un Taller de Cartografía Social. En el tercer apartado se exponen y se discuten los resultados. $Y$ al final se presentan las conclusiones.

\section{Marco teórico-conceptual}

El riesgo es un concepto compuesto por dos elementos: la presencia de una amenaza y la preexistencia de una vulnerabilidad, elementos que de manera aislada e independiente no representan riesgo alguno, pero que al interactuar dan lugar a la posibilidad de que se presente un desastre (Cardona, 2001). Dado que el riesgo se concibe como una anticipación posible o antesala para un desastre, este último se entiende como la materialización del riesgo cuando ya no se pueden evitar los daños, es decir, cuando los desastres ocurren en la realidad. Éstos, lo mismo que las amenazas, tienen diversas causas y, por lo general, son producto de la interacción no sólo entre sociedad y sistemas naturales, sino también entre sociedad y tecnología (Soares y Sandoval, 2016), lo cual genera efectos adversos en las personas, las comunidades, los bienes o servicios y el ambiente. En lo que concierne al presente trabajo, las amenazas tecnológicas provenientes de la actividad minera ocurren a partir de fallos no sólo en los sistemas tecnológicos (PNUMA, 2004), sino también en los sistemas económicos, políticos y sociales que regulan el uso de las tecnologías (Johnson y Covello, 1987).

Ahora bien, a finales de la década de 1990 se conformó un nuevo contenido y uso del concepto de riesgo, producto de varios factores, entre los que se encuentran los trabajos de la Organización de Naciones Unidas (ONU) y del Decenio Internacional para la Reducción de los Desastres, pues éstos incitaron numerosas reflexiones entre los investigadores de diferentes países en relación con el riesgo y los desastres, teniendo como eje de análisis la vulnerabilidad (García, 2005). En América Latina, esta corriente llevó a la formación de la Red de Estudios Sociales en Prevención de Desastres (LaRed) en 1992, institución que ha realizado varias investigaciones que abordan los desastres como procesos sociales y como problemas no resueltos del desarrollo, los cuales pueden prevenirse. No obstante, el aporte político-normativo de LaRed sostiene una perspectiva estructuralista, abstracta, mecánica, pasiva y homogénea de las 
comunidades afectadas (Sandoval, 2020). Por eso, en la actualidad, la vulnerabilidad se inclina a ser conceptualizada bajo la noción de resiliencia, a través de una amplia gama de disciplinas (por ejemplo, física, ingenieril, ecológica y del comportamiento) y de enfoques (rebotar hacia atrás, rebotar hacia delante y centrada en los márgenes) de reducción de riesgos de desastre (Sandoval, 2020).

De esta manera, la vulnerabilidad se presenta como un concepto múltiple en cuanto a su definición y diagnóstico, puesto que "no posee un valor absoluto, sino que dependerá de los tipos y valores de las amenazas existentes, de la escala de estudio, de la profundidad y de la orientación metodológica del mismo" (Climent, 2002, p. 15). De ahí que se desarrollen diferentes propuestas para comprenderla y, con ello, mitigar la ocurrencia e impacto de un desastre, entre las cuales se pueden identificar: 1) las que se refieren a la capacidad de respuesta, producto de la relación entre el entorno y el interno, ante la exposición a una determinada amenaza (Busso, 2001); 2) las que se enfocan en variables demográficas y culturales, tales como la clase, la etnia, la edad o el género (Fordham, 2007); 3) las que se expresan en relación con la exposición a una amenaza generada a partir de la condición social y económica (Blaikie, Cannon, Davis y Wisner, 1996); y 4) propuestas que se basan en una gran cantidad de variables que aumentan la magnitud de los desastres (Cardona, 2001; Wilches-Chaux, 1993).

Wilches-Chaux (1993) propone el concepto de vulnerabilidad global con el objetivo de destacar la interacción de diversos factores que convergen en una comunidad. Más tarde este concepto fue retomado y ampliado por Cardona (2001), quien incorporó el carácter multidimensional de vulnerabilidad (física, social, política, técnica, ideológico-cultural, educativa, ambiental e institucional). Así, la definición de ésta, de la cual parte la presente investigación, se refiere a las características y factores de una comunidad que influyen en su capacidad de absorber, anticipar, lidiar, resistir y recuperarse de los daños o de las amenazas. A la interacción de características y factores se les dará el nombre de vulnerabilidad global (Wilches-Chaux, 1993).

La amenaza y la vulnerabilidad representan, como dijimos al principio, una dupla inseparable en el análisis de riesgo. No sólo son producto de un análisis objetivo -técnico-, sino también subjetivo -sociológico- (López y Luján, 2000). El primer enfoque (el objetivo) fue el dominante durante mucho tiempo y argumenta que las estimaciones de riesgo pueden cuantificarse mediante la estadística. Así, el trabajo de Starr (1969) ofreció las bases científicas para establecer umbrales de riesgo aceptable que se pudieran utilizar en la toma de decisiones. En este sentido, la evaluación del nivel aceptable de riesgo se establece mediante la reiterada contrastación entre daño y beneficio, de tal forma que cuanto mayor beneficio produzca una actividad, más aceptable será el riesgo. Así mismo el autor observó, a partir de registros estadísticos, que los riesgos asumidos de manera voluntaria presentaban niveles más altos de aceptación que los impuestos, e interpretó este postulado como una ley universal.

Bajo el segundo enfoque (el subjetivo), la antropóloga Douglas y el politólogo Wildavsky (1982) reconocieron que el riesgo es una construcción social que 
hace uso de aproximaciones cualitativas y etnográficas (Ferrari, 2011). Según estos pensadores, las creencias y los valores compartidos por determinados grupos sociales y culturales influyen en la manera de considerar qué es riesgo y qué no lo es. A partir de éste, la aceptabilidad del riesgo se explica en función de cómo los intereses sociales influyen en la atención selectiva de los riesgos de las personas. (Douglas y Wildavsky, 1982). En otras palabras:

La cuestión de los niveles aceptables de riesgo forma parte de la cuestión de los niveles aceptables de vida y los niveles aceptables de moralidad y decencia, y no se puede hablar con seriedad del aspecto del riesgo mientras se evita la tarea de analizar el sistema cultural en el que se han formado los otros niveles. (Douglas, 1996, p. 127)

De esta forma, el riesgo se convierte en un asunto subjetivo que involucra juicios intuitivos "relacionados tanto con las estructuras personales, cognitivas, emocionales y de motivación, como con los ambientales, sociales, culturales y políticos” (Sjöberg y Drotzz-Sjöberg, 1994, p. 54).

En efecto, las posturas positivistas y la relativista otorgan a los valores distinta importancia, con lo cual enriquecen el análisis de riesgo; pero darle a éstos mayor importancia que a los otros, puede llevarnos a conclusiones incorrectas. Como señala Shrader-Frechette (1991), ambas posturas son reduccionistas, en particular cuando hay controversia en torno a los riesgos tecnológicos, en la que es fácil identificar dos grupos enfrentados: por un lado, los legos que serán los posibles afectados y, por el otro, los expertos y representantes de la industria. Por eso se propone evaluar los riesgos de manera integral. "Las decisiones se toman en condiciones de incertidumbre, y por tal motivo se deben realizar juicios de valor. Tener presentes los valores en los que descansa una evaluación de riesgos enriquecerá el análisis” (Ortega, 2014, p. 38).

Lo dicho por Shrader-Frechette (1991) se vincula a la teoría de la observación de segundo orden de Luhmann (1992). Para el sociólogo alemán, se puede hablar de riesgo cuando se presupone que quien lo percibe efectúa ciertas diferenciaciones; por ejemplo, la distinción entre los que deciden y los afectados. Así, los afectados esbozan teorías propias acerca de la conducta de riesgo de quienes deciden, y quienes deciden esbozan teorías propias acerca de la conducta de protesta de los afectados. En este sentido, Luhmann (1992) establece que la investigación moderna consiste en observar cómo observan los observadores para identificar qué distinciones hacen. De esta forma, "se obtienen experiencias, y ciertamente existen posibilidades de refinar y mejorar tales explicaciones, de equiparlas con una mayor complejidad y con posibilidades de comunicación más exactas" (p. 157).

\section{Marco metodológico}

Para analizar las percepciones de vulnerabilidad que expresan los diferentes actores (autoridades, asociaciones civiles, académicos, organizaciones sociales, 
activistas y pobladores) frente al riesgo minero en el río Sonora, se establecerá un "diálogo" entre ellos, de tal forma que se puedan identificar las similitudes y las diferencias entre sus respectivas narrativas. La idea es visibilizar las controversias en los discursos sobre vulnerabilidad. Dada la multiplicidad de ángulos a partir de los cuales se puede analizar la vulnerabilidad, se retoman las dimensiones de vulnerabilidad global de Wilches-Chaux (1993) para distinguir varias vulnerabilidades: física, técnica, económica, social, política, ideológico-cultural, educativa, ambiental e institucional. Éstas se definen como categorías de trabajo (véase tabla 1) para facilitar la sistematización de los discursos.

Tabla 1. Definición y operacionalización de las dimensiones de vulnerabilidad global

\begin{tabular}{|c|c|c|}
\hline Dimensión & Definición & Operacionalización \\
\hline Física & $\begin{array}{c}\text { Se refiere a la localización } \\
\text { de la población en áreas de riesgo } \\
\text { y a las deficiencias de resistencia } \\
\text { de los elementos expuestos } \\
\text { para absorber los efectos } \\
\text { que representa la amenaza } \\
\text { (Cardona, 2001; Foschiatti, 2007). }\end{array}$ & $\begin{array}{l}\text { La dimensión se observa a partir } \\
\text { de la ubicación de las comunidades } \\
\text { en el área de influencia de } \\
\text { accidentes provenientes de la } \\
\text { actividad minera (por ejemplo, falla } \\
\text { de presa de relaves, accidentes de } \\
\text { transporte, falla de tubería, } \\
\text { hundimientos o subsidencia, } \\
\text { derrumbes, derrame de sustancias } \\
\text { químicas e incendio y explosiones). }\end{array}$ \\
\hline Técnica & $\begin{array}{c}\text { Incapacidad de acceder o poner } \\
\text { en práctica técnicas adecuadas } \\
\text { para evitar los posibles impactos } \\
\text { negativos, tanto sociales } \\
\text { como ambientales. }\end{array}$ & $\begin{array}{c}\text { Baja capacidad de almacenamiento } \\
\text { y falta de impermeabilización } \\
\text { de las presas de jales. }\end{array}$ \\
\hline Económica & $\begin{array}{l}\text { Ausencia de recursos económicos } \\
\text { de los miembros de una comunidad. }\end{array}$ & $\begin{array}{l}\text { Insuficiencia de ingresos } \\
\text { y desempleo. }\end{array}$ \\
\hline Social & $\begin{array}{l}\text { Baja cohesión interna, ausencia de } \\
\text { liderazgo comunitario afectivo para } \\
\text { prevenir o responder a desastres. } \\
\text { También se expresa por falta de } \\
\text { recursos humanos y materiales } \\
\text { en el sector salud. }\end{array}$ & $\begin{array}{l}\text { Esta dimensión se observa } \\
\text { a través de la ausencia de confianza } \\
\text { entre vecinos y la falta de recursos } \\
\text { humanos y materiales } \\
\text { en el sector salud. }\end{array}$ \\
\hline Política & $\begin{array}{c}\text { Nivel de autonomía de una } \\
\text { comunidad para la toma de } \\
\text { decisiones que la afectan, así } \\
\text { como su capacidad de gestión } \\
\text { y de negociación ante gobiernos } \\
\text { y empresas. }\end{array}$ & $\begin{array}{l}\text { Baja participación ciudadana } \\
\text { y falta de información } \\
\text { para la toma de decisiones. }\end{array}$ \\
\hline $\begin{array}{l}\text { Ideológico- } \\
\text { cultural }\end{array}$ & $\begin{array}{c}\text { Acciones desplegadas por la } \\
\text { comunidad ante una amenaza } \\
\text { que estimulen sus fortalezas } \\
\text { y capacidades para la prevención } \\
\text { de accidentes mineros. }\end{array}$ & $\begin{array}{l}\text { Desinterés comunitario } \\
\text { para prevenir accidentes mineros. }\end{array}$ \\
\hline
\end{tabular}




\begin{tabular}{|c|c|c|}
\hline Educativa & $\begin{array}{c}\text { Falta de preparación y de acceso } \\
\text { al conocimiento sobre las causas } \\
\text { y las razones por las cuales se } \\
\text { presentan los desastres. }\end{array}$ & $\begin{array}{c}\text { Falta de programas de prevención y } \\
\text { recuperación de accidentes mineros } \\
\text { (por parte de la empresa), con el fin } \\
\text { de contrarrestar las vulnerabilidades. }\end{array}$ \\
\hline Ambiental & $\begin{array}{c}\text { La explotación minera inadecuada } \\
\text { conduce al deterioro ambiental } \\
\text { (por ejemplo, contaminación } \\
\text { del agua, del suelo, del aire, } \\
\text { deforestación y afectación } \\
\text { del hábitat de animales silvestres). }\end{array}$ & $\begin{array}{c}\text { Deterioro del medio ambiente } \\
\text { (contaminación del agua, del suelo, } \\
\text { del aire, deforestación y afectación } \\
\text { del hábitat de animales silvestres). }\end{array}$ \\
\hline Institucional & $\begin{array}{c}\text { Se refiere a burocracia, politización } \\
\text { y corrupción en el Estado y los } \\
\text { servicios públicos, que impiden } \\
\text { respuestas adecuadas y ágiles } \\
\text { en caso de desastre. }\end{array}$ & $\begin{array}{c}\text { Grado de confianza } \\
\text { en las instituciones públicas, } \\
\text { asínomo su incapacidad para } \\
\text { regular las empresas y gestionar } \\
\text { el proceso de riesgo-desastre. }\end{array}$ \\
\hline
\end{tabular}

Fuente: elaboración propia con base en Wilches-Chaux (1993 y 1998), Foschiatti (2007) y Cardona (2001).

El análisis que aquí se realiza tiene la intención de obtener una perspectiva profunda y compleja del problema. Por consiguiente, se utiliza un enfoque cualitativo que permita analizar las percepciones de los actores en torno a las vulnerabilidades. Para ello se emplea como método el análisis narrativo del discurso. Una narrativa en el discurso es aquella integración de eventos que producen un significado, valores y sentido de la vida de las personas mediante sus preocupaciones, tensiones, contradicciones y acciones (Urra, Muñoz y Peña, 2013; Vallejos y Garrido, 2019). Así, esta estrategia discursiva permite acceder a la percepción o entendimiento de los eventos sin dejar de entender las ambivalencias, tensiones y contradicciones en las cuales se mueven los actores.

La recopilación de los discursos de los actores involucrados se llevó a cabo mediante la aplicación de entrevistas abiertas y la realización de un Taller de Cartografía Social. Se eligió la entrevista como herramienta metodológica debido a su flexibilidad y a su efectividad para la obtención, en detalle, de las perspectivas y experiencias de los participantes a partir de sus propias normas, valores y lenguaje. De igual modo, la cartografía social permite una mirada geográfica más allá de los aspectos físicos del proceso cartográfico e ilustra las percepciones, experiencias, valores, sentimientos y conocimientos sociales, culturales e históricos de quienes la construyen. La selección de los participantes, en cada una de las herramientas de investigación (entrevistas y taller), se realizó a través del muestreo por cuotas y voluntarios. El número de participantes se estableció a partir del criterio de saturación de información. El material recopilado (grabado y transcrito) fue codificado y se analizó la narrativa con el software NVivo 12 Pro. 
El trabajo de campo se realizó en tres etapas. En la primera, de agosto a septiembre de 2018, se aplicaron siete entrevistas abiertas a expertos. ${ }^{2}$ Detrás del perfil de este grupo de actores, se encuentra el proceso de expansión de los desarrollos tecnológicos, los cuales atrajeron una pluralidad de actores y desató una variedad de intereses; por ello se decidió considerar una gama más amplia de roles representados por los expertos. En consecuencia, se amplió el enfoque de éstos, más allá de los conocimientos científicos, para incluir aquellas posturas de personas expertas en un determinado campo de conocimiento en relación con la minería y que tienen algo que poner en juego en el proceso simbólico y político de ésta en el estado de Sonora. Así, en calidad de expertos, se entrevistaron a algunos actores en los siguientes roles:

a) Autoridades en el ámbito público (AP): se consideran los actores que tienen un papel determinante en la toma de decisiones y que cuentan entre sus recursos el abordaje del conocimiento experto desde una mirada de la gestión de la política minera. En este sentido, se entrevistó a un representante de la Dirección General de Minería (adscrita a la Secretaría de Economía del Estado de Sonora) y de la Procuraduría Federal de Protección al Ambiente (PROFEPA), delegación Sonora.

b) Asociaciones civiles (AC): son actores independientes de las autoridades, que cuentan entre sus recursos el abordaje del conocimiento experto encaminado hacia el desarrollo de la industria minera en Sonora. Para recopilar la información se tuvieron reuniones con un representante del Clúster Minero de Sonora, A. C. y con un integrante de la Asociación de Ingenieros Metalurgistas y Geólogos de México, A. C. (AIMMGM), distrito Sonora.

c) Académicos (Acad.): actores que, desde instituciones académicas, cuentan entre sus recursos el abordaje del conocimiento experto orientado a la formación profesional y a la producción de investigación científica aplicada a la minería, metalurgia y geología. En este caso, se platicó con un profesor de la carrera de Ingeniero Minero de la Universidad de Sonora (Unison).

d) Organizaciones de la sociedad civil (OSC): son aquellos actores independientes de las autoridades los cuales cuentan entre sus recursos el abordaje del conocimiento experto centrado en revertir los costos sociales, ambientales y laborales de la industria minera. Se consideran las OSC de carácter externo a la región de estudio, por lo cual se conversó con un representante del Proyecto sobre Organización, Desarrollo, Educación e Investigación (PODER, por sus siglas en inglés) y con un dirigente de la Sección 65 del Sindicato Minero Nacional de Trabajadores Mineros, Metalúrgicos, Siderúrgicos y Similares de la República Mexicana (SNTMMSRM).

En la segunda etapa, para conocer el discurso de la sociedad civil organizada (SOC) de carácter local, se llevó acabo un Taller de Cartografía Social el 12 de

2 En este trabajo la definición de "experto" está lejos de los estándares de producción científica, de sus atributos de verdad o falsedad del saber. En cambio, la acepción empleada se acerca a la de aquellos que toman decisiones o acciones en el terreno práctico. "La experticia puede comprenderse, en consecuencia, como una forma elaborada de la influencia social, que ha conseguido cierta especialización al apoyarse en un marco institucional y en organizaciones particulares" (Pinilla, 2012, p. 122). 
noviembre de 2018, en la comunidad de Huépac. A éste asistieron seis activistas, con edades entre los 35 y los 75 años, de distintas ocupaciones (ganaderos, comerciantes, amas de casa, servidores públicos y maestros) en la región del río Sonora, quienes fueron afectados por el derrame y se organizaron a través de los Comités de Cuenca río Sonora (CCRS). Durante dos horas, los activistas dialogaron sobre las condiciones de vulnerabilidad de las comunidades frente a las operaciones mineras. Para ello se les solicitó, entre otras cosas, ubicar en un mapa de la región las vulnerabilidades que, a su consideración, estaban presentes en el río Sonora.

En la tercera etapa se realizaron los días 14, 15 y 16 de septiembre de 2019 siete entrevistas abiertas a pobladores de los municipios de Banámichi, San Felipe de Jesús, Huépac, Aconchi, Baviácora y Ures. Sus edades oscilaron entre 40 y 75 y tenían diversas ocupaciones: ganaderos, agricultores, comerciantes, amas de casa, servidores públicos, mineros y jubilados. El objetivo era obtener sus percepciones sobre las condiciones de vulnerabilidad y su posicionamiento respecto al riesgo minero.

\section{Análisis de resultados}

A continuación, se muestran los resultados del análisis del discurso narrativo. Para facilitar su presentación, se utilizó la herramienta de mapa social para observar no sólo las relaciones entre actores (los expertos y legos), sino también las relaciones entre sus posturas sobre las dimensiones de vulnerabilidad. ${ }^{3}$ Según Martín (1999), el sociograma o el mapa social tiene como objetivo representar de forma gráfica relaciones de distinto tipo entre un conjunto de actores, lo cual aporta a la investigación una perspectiva de lo que está pasando y por dónde los implicados deciden que han de desarrollarse las propuestas de actuación.

En la figura 2 se puede identificar un mapa social para cada dimensión de vulnerabilidad analizada, en donde se encuentran representados los actores en tres tipos de organización: 1) los expertos (autoridades, asociaciones civiles, académicos y organizaciones de la sociedad civil), representados por un triángulo; 2) los legos, que integran a los activistas, representados por un círculo; y 3) la comunidad, representada por un rectángulo. Así mismo, sobre la base del análisis del discurso, se exponen las relaciones entre estos actores, a saber: a) acuerdo en hechos y actitud o valoración ante éstos (no hay conflicto), b) acuerdo en el hecho pero desacuerdo en la actitud frente a éste, y c) desacuerdo en hechos y/o actitudes respecto a éstos (conflicto o controversias) (véase figura 2).

3 Cabe aclarar que, en el presente trabajo, no se utiliza el mapa social para identificar roles y relaciones de poder entre actores; más bien éste se utilizó para representar las diferentes posturas (similares, diferentes e indiferentes) sobre las dimensiones de vulnerabilidad ante el riesgo minero en el río Sonora, las cuales se identificaron tras el análisis del discurso de los actores seleccionados. Para estar al tanto de las organizaciones que, en los últimos años, han mantenido acciones colectivas y relaciones de colaboración en el río Sonora, consúltese el trabajo de Lugo y Lara (2020). 


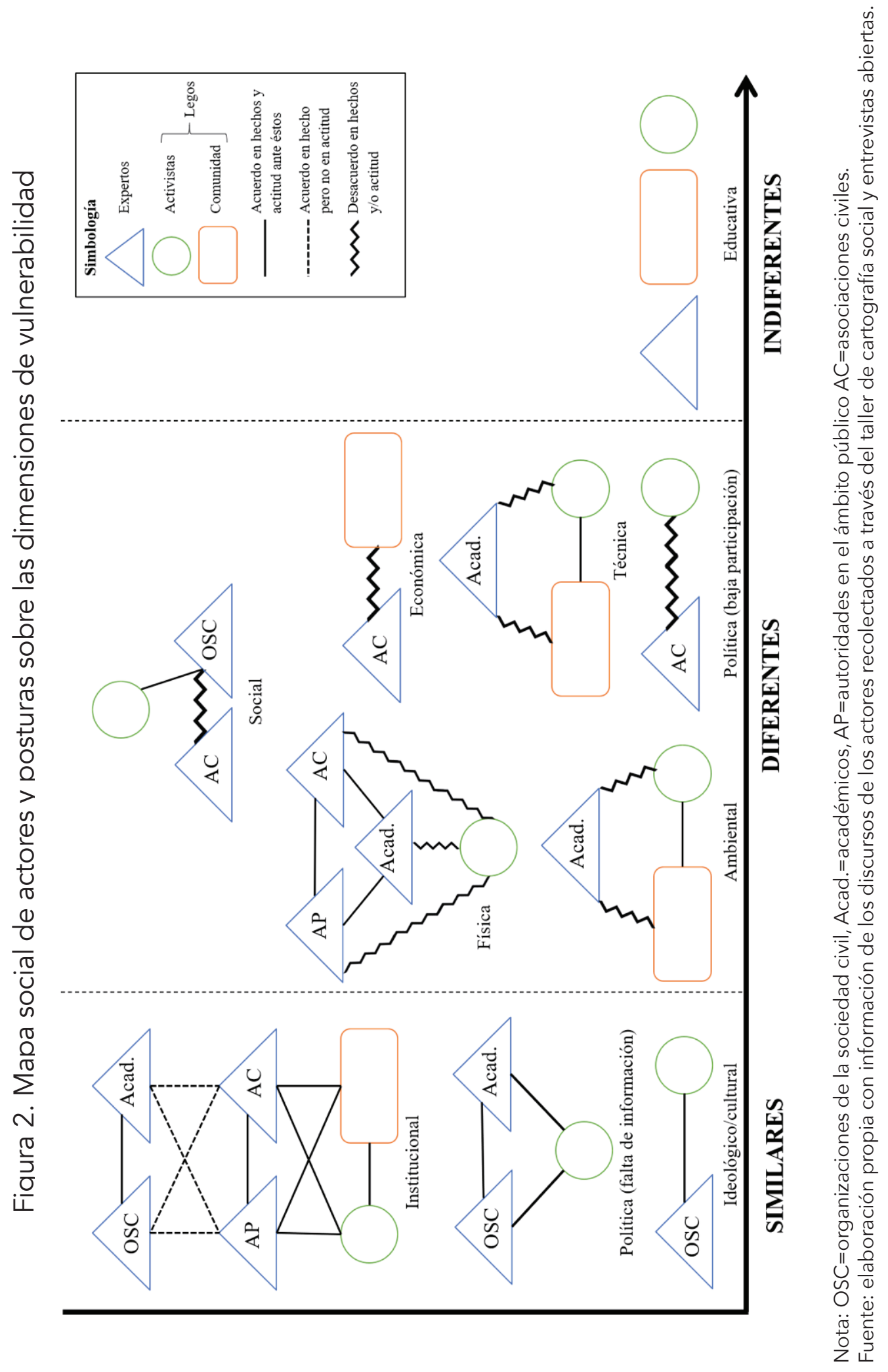


Analizando las diferentes posturas respecto a la vulnerabilidad, se identifican tres grupos: 1) las posturas similares sobre las dimensiones de vulnerabilidad, en las cuales tanto expertos como legos muestran puntos de acuerdo sobre ciertos hechos, a saber, la vulnerabilidad ideológico-cultural, la política (referente a la falta de información) e institucional; 2) las posturas diferentes sobre las dimensiones de vulnerabilidad y, por tanto, controversiales entre los actores (manifestándose puntos de acuerdo y desacuerdo), las cuales resultaron ser, para legos y expertos, la ambiental, la política en relación con una baja participación ciudadana, la técnica, la física, la económica y la social; y 3) las posturas indiferentes o de poco interés, como la educativa (véase figura 2). A continuación, con base en las percepciones de expertos y legos, se desarrollan las posturas de los actores en cada dimensión de vulnerabilidad y la clasificación de éstas en los grupos antes sugeridos.

4.1 Grupo 1: Posturas similares de las dimensiones de vulnerabilidad

a) Vulnerabilidad ideológico-cultural

Esta dimensión, que percibieron expertos y legos, se expresa a partir del desinterés comunitario para prevenir los accidentes mineros. Según un experto, el desinterés se ubica en los municipios de Cananea, Arizpe, Banámichi y San Felipe de Jesús. En el caso de Arizpe, comentó que es el municipio donde la mina Las Chispas está más alejada de la población: "por eso no se preocupan por la prevención de accidentes mineros" (Entrevista con OSC, comunicación personal, 18 de septiembre de 2018).

Si bien los legos no ubican el desinterés por prevenir accidentes en ningún lugar específico, sí comparten la postura de los expertos, al reconocer que esta indiferencia es característica de todos los pobladores del río Sonora. La percepción de la vulnerabilidad ideológico-cultural queda de manifiesto cuando se señala que, la mayoría de las veces, los pobladores hablan "sin tener sustento, pero tampoco intentan poner una solución o proponer una estrategia que conlleve a que tengamos conocimiento para mejorar las condiciones de la región" (Entrevista con C. N., poblador de Aconchi, comunicación personal, 14 de septiembre de 2019).

\section{b) Vulnerabilidad política (en relación con la falta de información)}

En relación con esta dimensión, captada a través de la baja participación ciudadana y la falta de información para la toma de decisiones, tanto expertos como legos se manifestaron en sus discursos con algunas coincidencias, pero también con diferencias. Las coincidencias se establecieron en el elemento falta de información; esto es, las OSC y los académicos cuestionaron el papel de las autoridades y de la empresa minera. Estos actores no informaron a los pobladores sobre el derrame; por lo tanto, los expertos resaltan la necesidad de contar con información clara y veraz de lo que se está manejando en las explotaciones mineras: “¿Qué pudiera suceder en caso de un derrame? ¿Cómo lo contrarrestamos? Eso sería una obligación de parte de la autoridad, que hiciera 
esa exigencia a las empresas" (Entrevista con OSC, comunicación personal, 19 de septiembre de 2018).

Coincidiendo con los expertos, los legos consideraron que sí hay información proporcionada por los medios de comunicación, pero que ésta no proviene de las instituciones del Estado ni de las empresas mineras, lo cual genera inseguridad entre los habitantes, en particular después del derrame. Por consiguiente, los legos indicaron que las mineras deben interactuar con la comunidad a través del acceso a la información y no sólo acerca de "cómo está actuando [la empresa] en cuanto políticas de cuidado ambiental y de salud" (Entrevista con C. N., poblador de Aconchi, comunicación personal, 14 de septiembre de 2019), sino también acerca de cuáles tierras y con qué materiales están contaminadas, para que la población tome los cuidados necesarios. "Alguien que viniera y dijera, pusieran en el ayuntamiento o en las tiendas: 'Las tierras están contaminadas con este material'. Nunca ha habido una información directa con la ciudadanía" (Entrevista con E. B., poblador de San José de Baviácora, comunicación personal, 14 de septiembre de 2019).

\section{c) Vulnerabilidad institucional}

Considerando el actuar del Estado en casos de desastre, algunos expertos también fueron críticos. Cabe señalar que, según lo establecido tanto en la anterior dimensión (política) como en ésta (institucional), se observó que el concepto de "experto" no es unívoco, pues abarca una amplia variedad de colectivos bien diferenciados entre sí, dependientes del terreno político en el cual se posicionen y del manejo que hagan de su ética profesional. Es decir, las OSC que buscan revertir los costos sociales, ambientales y laborales de la minería, y los académicos, muestran una postura más crítica que las autoridades del ámbito público y que las AC "pro minería” (enfocadas al desarrollo de la industria minera).

Esta postura crítica se advierte en el momento en que los académicos señalaron que la desconfianza en las instituciones públicas fue una situación que estuvo presente durante el derrame, ya que éstas no han hecho bien su trabajo; por ejemplo, las instituciones públicas "no tendrían que haber desviado el dinero para construir plantas de tratamiento que el gobierno debió haber construido y mejor haberlo dedicado a la remediación ambiental" (Entrevista con Acad., comunicación personal, 10 de septiembre de 2018).

Respecto a la posición de los legos, ésta coincide con los discursos de los expertos al manifestar también una desconfianza en las instituciones públicas, debido a la percepción de que tienen oscuros intereses o vínculos con el poder económico y político. Lo anterior confirma que, para entender las respuestas sociales ante un riesgo, es necesario considerar la evaluación hecha por los sujetos sobre las instituciones que promueven la actividad minera y la gestionan, así como la credibilidad y confianza que éstas merecen. Expresiones relacionadas con lo anterior, fueron las siguientes: "Pero [la minería] se colude con las autoridades para decirnos no tengan problemas, eso no es cierto, que daña. Pero claro que daña, es cuestión de costos [...]. Es más barato tumbar 
un cerro, triturarlo y rociarles químicos" (Activista 1, Taller de Cartografía Social, comunicación personal, 12 de noviembre de 2018). "Las autoridades nos dijeron que ya estaba buena el agua para tomar. Lo que querían ellos es que nos olvidáramos de eso, que no tenía nada, y nosotros viendo ahí el cochinero [derrame]" (Entrevistas a R. T. y a D. A., pobladores de San José de Baviácora, comunicación personal, 14 de septiembre de 2019).

4.2 Grupo 2: Posturas diferentes de las dimensiones de vulnerabilidad a) Vulnerabilidad ambiental

En relación con la vulnerabilidad ambiental, Vega, Cirett, Parra y Zavala (2011) explican que la subcuenca del río Sonora - al igual que la del río San Miguel y la del río Zanjón, que coinciden más o menos con el área de estudio- se encuentra en una situación de déficit, ya que el volumen de agua concesionado a la agricultura y a la minería es mayor que la recarga de agua en las respectivas subcuencas. Una situación similar la perciben los pobladores y los activistas, quienes comentaron que el problema del río Sonora es el agua, queja principal de los agricultores. Además, señalan que la actividad minera es la causante principal de la escasez de este recurso.

Activista 2: Pero todo el río es problema de agua porque se quejan los agricultores de que no hay agua.

Activista 3: La mina de Banámichi también está extrayendo mucha agua.

Activista 2: Es que mediáticamente nos han hecho creer que es la falta de lluvia.

Activista 3: Eso es mentira.

Activista 2: No es cierto, es esa extracción exagerada de agua (Taller de Cartografía Social, comunicación personal, 12 de noviembre de 2018).

A diferencia de los legos, los expertos tratan de aminorar la relevancia de la vulnerabilidad ambiental relacionada con el alto consumo de agua de la minería, centrando su discurso en otros problemas ambientales como, por ejemplo, la falta de tratamiento de las aguas negras que se descargan en el río. Al respecto, lo expertos señalan que el gobierno no ha hecho nada por solucionar este problema; en cambio, la minería cuenta con protocolos y controles.

Pero si de vulnerabilidades hablamos, yo le pondría mayor atención a que las aguas negras no vayan al río, porque éstas no tienen protocolos y las minas sí. Los habitantes de Ures se tragan los desechos, así ha sido por muchos años, el gobierno lo sabe y no ha hecho nada. (Entrevista con Acad., comunicación personal, 10 de septiembre de 2018)

Lo anterior se contrapone con un artículo de Celis (1992), en donde se argumenta que el río Sonora no sólo ha sido cuerpo receptor de asentamientos humanos y actividades agrícolas y ganaderas, sino también de descargas de beneficio de minerales. Dicho estudio se corrobora por medio de un muestreo 
realizado en las columnas de agua del río Sonora y su afluente, el río Bacauchi, en el periodo de septiembre de 1984 a mayo de 1985 (Gómez-Álvarez, Ortega-Romero y Yocupicio-Anaya, 1990). Mediante dicho muestreo se determinó que en el arroyo Correo Viejo, afluente del río Sonora, se originan

contaminaciones por metales pesados para abrevaderos, uso doméstico y en los suelos de los lugares denominados Ojo de Agua de Arvallo, Genovérachi, Los Conejos, Cañada Ancha, El Pozo Nuevo, La Escondida, Mututicachi, La Higuera, Unámichi, Mesa Linda, Cerro Colorado, Santa Lucía, Chinapa, Buenavista y Arizpe, que se encuentran localizados en los márgenes de estos ríos. (Gómez-Álvarez, Ortega-Romero y Yocupicio-Anaya, 1990, p. 11)

b) Vulnerabilidad política (baja participación ciudadana en la toma de decisiones)

Hay que recordar que la dimensión de vulnerabilidad política se conformó a partir de dos elementos: falta de información y baja participación ciudadana en la toma de decisiones. En párrafos anteriores se abordó el elemento (falta de información) que registró posturas similares entre expertos y legos. A continuación, se desarrolla el que generó una de las principales controversias detectadas en la comparación de los discursos y que se refiere a la baja participación ciudadana.

Para los expertos, los pobladores del río Sonora no participan en la toma de decisiones sobre la actividad minera en sus territorios, porque están más bien interesados en obtener una ganancia económica. En contraste, los legos explicaron que la baja participación se debe a la desconfianza y a la decepción en los políticos, quienes no mostraron interés en sus demandas. Con esto se afirma que los legos involucran muchas más cuestiones en sus definiciones y evaluaciones en torno a los riesgos, que aquéllas reconocidas por el esquema reduccionista del conocimiento experto (Otway y Cohen, 1975; Slovic, 2000). Al respecto se señala que:

Es poca la gente que participa. ¡Ah! Para qué andar con eso, si les importa poco, que son políticos. A mí me han dicho: ¡Estás loca, no te van a hacer caso! Son unos ricachones que no les importa el pueblo, ni los pobres, ellos viven felices con sus empresas [...]. Hay mucha gente decepcionada de los políticos, de la gente de arriba. (Entrevista con E. B., poblador de San José de Baviácora, comunicación personal, 14 de septiembre de 2019)

\section{c) Vulnerabilidad técnica}

En relación con la vulnerabilidad producto de prácticas y técnicas inadecuadas, varios estudios (Celis, 1992; Gómez, Romero y Yocupicio, 1990; Moreno, 1992) han destacado la baja capacidad de almacenamiento y la falta de impermeabilización de la presa de jales de la mina Buenavista del Cobre. Esta vulnerabi- 
lidad se presentó en los discursos de los legos. Algunas percepciones en torno a esto fueron: "Tenemos el temor que vuelva a suceder. Ése es el problema. Que hagan buenas presas para que no se derrame” (Entrevista con C. C., poblador de Ures, comunicación personal, 16 de septiembre de 2019); “los represos quién sabe cómo estén construidos y cuándo vaya a haber, ponle, un descuido humano o simplemente por la naturaleza, que llegue a llover mucho y el represo se desborda" (Activista 1, Taller de Cartografía Social, comunicación personal, 12 de noviembre de 2018); "hace muchos años que tienen contaminado el río, si todo el tiempo han soltado los represos porque tienen 10 kilómetros de largo" (Entrevista con M. A., poblador de Huépac, comunicación personal, 16 de septiembre de 2019).

En contraste, los expertos no consideraron la vulnerabilidad técnica, pues argumentan que las empresas cuentan con las tecnologías suficientes para lidiar con las amenazas provenientes de las operaciones mineras (ruptura de presa de relaves, accidentes de transporte, falla de tubería, hundimientos o subsidencia, desprendimientos de roca y derrumbes, derrame de sustancias químicas e incendios y explosiones). Un entrevistado señaló que "si el desastre es tal, por ejemplo, un incendio, un derrumbe, una fuga de cianuro, un derrame, existen protocolos de atención. Todas las empresas los tienen" (Entrevista a los Acad., comunicación personal, 10 de septiembre de 2018).

\section{d) Vulnerabilidad física}

La dimensión física de la vulnerabilidad se refiere a la localización de la población en áreas de riesgo y a las deficiencias de resistencia de los elementos expuestos para absorber los efectos que representa la amenaza (Cardona, 2001; Foschiatti, 2007). Así, “la sismorresistencia de un edificio, la ubicación de una comunidad en el área de influencia de un deslizamiento o en el cauce de un río, son ejemplos de la dimensión física de la vulnerabilidad" (Cardona, 2001, p. 12). En este caso de estudio, la dimensión se observa a partir de la localización de las comunidades en el área de influencia de los accidentes de la actividad minera. Al respecto, debe señalarse que los asentamientos de población son, en términos relativos, inamovibles, por lo que la ubicación de las operaciones mineras y, en consecuencia, de sus zonas de riesgo deben analizarse a partir de la ubicación de la mina y de la interacción con otros elementos en el área (las comunidades), así como con los mecanismos de propagación de los impactos de un posible desastre.

El derrame en el río Sonora, vinculado a la presa de jales de la empresa minera, visibiliza la vulnerabilidad tanto técnica (ya señalada) como física de las comunidades expuestas. Así, la presa de jales, su ubicación y la interacción con las comunidades en el área de afectación constituyen una importante amenaza que debe tenerse en cuenta. Ésta y sus posibles impactos se potencian a la luz de los planes de expansión de la mina Buenavista del Cobre, los cuales incluyen la construcción de una nueva presa de jales a 30 kilómetros de la comunidad de Bacanuchi - primera comunidad afectada por el derrame de 2014- en el municipio de Arizpe y próxima a los afluentes del río Sonora. La presa “ocupará 
una superficie aproximada de 4000 ha y tendrá una altura máxima de $200 \mathrm{~m}$, que se alcanzará en aproximadamente 40 años. El volumen de almacenamiento estimado será de 3000 millones de $\mathrm{m}^{3}$ y el de la cortina contenedora de 250 millones de $\mathrm{m}^{3}$ " (Orozco y Muhech, 2012, p. 1).

La presencia de esta nueva amenaza, en combinación con la vulnerabilidad física de las comunidades asentadas a lo largo del río Sonora, aumenta el riesgo de otro derrame de sustancias tóxicas al río. En el discurso de los legos, lo anterior se manifestó a través de la preocupación por la ocurrencia de algún accidente que involucre a la presa de jales:

Sí, puede volver a suceder [el derrame] cuando menos lo piense [...]. A nosotros no se nos hace bueno cómo de la noche a la mañana se nos va a reventar la presa, y nos va a venir otra vez a hacer daño. Eso es la preocupación, el futuro de nuestros hijos: no hay nada, si todo el cochinero se está viniendo para los pueblitos estos. (Entrevistas a R. T. y a D. A., San José de Baviácora, 14 de septiembre de 2019)

Al igual que la vulnerabilidad técnica, los expertos consideran que, en relación con la vulnerabilidad física, la industria minera también cuenta con las tecnologías y los protocolos suficientes para lidiar con dichos accidentes. Un experto manifestó que las características principales de la minería a cielo abierto son "modernidad, nuevas tecnologías, nueva química, más seguridad” (Entrevista a las AP, comunicación personal, 7 de septiembre de 2018).

Lo dicho por estos expertos recuerda a Beck (2015), quien señala que en la modernidad los riesgos se desenvuelven en un mundo microscópico, invisible e imperceptible (por ejemplo, virus, radiación, campos electromagnéticos, niveles elevados de arsénico en el agua, contaminación química y residuos de fitosanitarios en los alimentos), en el que los seres humanos no perciben de inmediato tales riesgos y, por tanto, la opinión experta es esencial. De ahí que el entendimiento y evaluación de los riesgos modernos esté dado por los expertos, lo cual los convierte en portadores de un "gran poder", en quienes pueden normalizar, reducir o ignorar ciertos riesgos o, por el contrario, especificar lo que se desconoce y alertar sobre ellos (Iturralde, 2014).

Lo anterior se observa con claridad en los discursos de las autoridades (AP) y de las AC prominería, que con el fin de afirmar que los riesgos de la actividad son bajos, acompañan algunas vulnerabilidades (por ejemplo, física, técnica y ambiental) con palabras como "normas", "regulación”, "procedimientos", "tecnología”, “modernidad” y "seguridad”, entre otras. Es decir, algunos expertos tratan de disminuir los riesgos centrando la discusión en que las vulnerabilidades pueden ser atendidas, controladas o resueltas, pero tales afirmaciones contradicen los discursos de los legos.

\section{e) Vulnerabilidad económica}

La insuficiencia de recursos no fue señalada como vulnerabilidad económica en los discursos de los expertos. Incluso los entrevistados consideran que la falta 
de ingreso o empleo se resolvió en el momento de "instalarse" una mina en las comunidades, ya que ésta representa una oportunidad de trabajo y detona la economía del lugar, "al llegar gente que compró más gasolina, que compró burritos en la esquina o que pidió una casa para rentar" (Entrevista a las AC, comunicación personal, 10 de septiembre de 2018). Entretanto, los legos cuestionaron el tipo de empleo que ofrece la minería, el cual ocupa por lo general personal especializado de otras partes del país y del mundo. Ese personal obtiene los mejores empleos y deja los puestos de bajo nivel a los pobladores de las comunidades del río Sonora.

Activista 2: Pensando en positivo, yo sí pensaría en que [la minería] realmente genera empleo.

Activista 1: Genera empleo sí, pero qué calidad de empleo y qué prestación.

Activista 2: Lo que iba aclarar es que el empleo más grande que están generando, no sé si me contradigo un poco, no son personas de aquí, emplean lo más bajo [puestos de trabajo de bajo nivel] del río Sonora" (Taller de Cartografía Social, comunicación personal, 12 de noviembre de 2018).

\section{f) Vulnerabilidad social}

Esta dimensión de la vulnerabilidad se captó a través de dos elementos: la falta de acceso a los servicios de salud y la ausencia de confianza en los vecinos. En el primero, los expertos presentaron puntos de vista contradictorios. Por un lado, se estableció que la falta de acceso a los servicios de salud se resolvió en el momento en que llegó la minería, ya que "se comprometieron a realizar jornadas de salud" (Entrevista a las AC, comunicación personal, 6 de septiembre de 2018). Por el otro lado, se comentó que las poblaciones del río Sonora tienen acceso a los centros de salud, pero no acuden a éstos porque no tienen médicos, quienes sólo "se encuentran en las cabeceras municipales, siendo Ures el municipio con mayor uso de los servicios de salud" (Entrevista a las OSC, comunicación personal, 18 de septiembre de 2018).

Los legos comparten también la percepción de falta de recursos en el servicio de salud en la región del río Sonora. Señalaron que los centros de salud de la región no sólo carecen de personal, sino también de medicamentos y de equipo médico: "Hay centros de salud, pero no tienen suficientes medicinas. Con decirle que el año pasado hicimos una actividad para comprar un baumanómetro que no había para la presión, el estetoscopio. Hay veces que no tienen [los centros de salud] lo más indispensable" (Entrevista con E. B., poblador de San José de Baviácora, comunicación personal, 14 de septiembre de 2019).

En relación con el tema de la confianza entre vecinos, se parte de la idea de que abordarlo permite entender los procesos de cohesión social en una comunidad, lo cual propicia acciones de prevención o de respuesta a los desastres. En este caso, los expertos señalaron que es muy común en el río Sonora que la población no confíe en sus vecinos, debido a la existencia de élites de poder que manipulan la opinión de ésta. "Esto deriva en una desconfianza alimentada constantemente por estos grupos políticos" (Entrevista a las OSC, comunicación 
personal, 18 de septiembre de 2018). En cambio, para los legos, esta dimensión de la vulnerabilidad no emergió como parte importante en sus discursos.

4.3 Grupo 3: Posturas indiferentes o de poco interés en las dimensiones de vulnerabilidad

a) Vulnerabilidad educativa

Aun cuando en comunidades bajo constante riesgo es necesaria educación o capacitación para hacer frente a las amenazas, prevenir desastres y, en consecuencia, actuar de manera adecuada, ni los expertos ni los legos percibieron la dimensión educativa de la vulnerabilidad. En los discursos de expertos y de legos no emergió ningún cuestionamiento por la inexistencia de pláticas o talleres impartidos por el sector público o privado relacionados con el riesgo minero y con la prevención de desastres. Aunque un experto señaló que si bien las empresas mineras siempre tienen un plan de contingencia, no fue sino a partir del derrame que éstas se dieron cuenta de hasta dónde podría llegar el problema. No obstante, en vez de que el experto considerara la falta de capacitación como una vulnerabilidad educativa, la consideró "una oportunidad para que las empresas amplíen sus horizontes" (Entrevista con AC, comunicación personal, 6 de septiembre de 2018).

\section{Conclusiones}

La evaluación del riesgo tecnológico es un tema relevante que implica tomar decisiones en condiciones de incertidumbre y ante una diversidad de actores e instituciones que cuentan con distintos intereses y valores, tanto ambientales y culturales como económicos y políticos. En el presente trabajo se analizaron los discursos expresados por diferentes actores (autoridades del ámbito público, activistas, asociaciones civiles, organizaciones sociales, académicos y pobladores) y las percepciones manifestadas sobre la vulnerabilidad frente al riesgo minero en el río Sonora, México. El trabajo aportó ejemplos de cómo las diferencias y las similitudes en las percepciones de las vulnerabilidades entre los actores involucrados enriquecen y mejoran la comprensión y el abordaje del riesgo minero.

En relación con el concepto de vulnerabilidad, el estudio permitió observar su cualidad dinámica, ya que ésta puede transformarse, acumularse o disminuirse, pero con dificultad eliminarse (Ruiz, 2005). De modo que, al integrar los discursos de los diferentes actores, se llega al corolario del análisis: el riesgo percibido en el río Sonora es producto de un proceso de vulnerabilidad física y técnica progresiva, acelerado por el resurgimiento de la minería tanto a cielo abierto como subterránea, en donde la vulnerabilidad ambiental (por la sobreexplotación de la cuenca para las operaciones mineras) y la vulnerabilidad política (relacionada con la desconfianza institucional) son ejemplos de las principales controversias, entre expertos y legos, que requieren dirimirse en aras de avanzar hacia una buena gestión de riesgos. 
No obstante, es necesario poner la atención en dos situaciones críticas identificadas en este trabajo. La primera de ellas tiene que ver con ciertas posturas que reflejan con claridad el positivismo ingenuo de los expertos, quienes asumen cierta linealidad en las dinámicas que se desarrollan en la región; por ejemplo, el suponer que los beneficios económicos y sociales llegan por la sola presencia de la actividad minera, por lo que la vulnerabilidad socioeconómica, de existir, se resuelve de inmediato. Lo anterior resulta incompatible con la realidad percibida por los legos, quienes señalan la precariedad de los empleos a los cuales pueden acceder; también con el problema de los servicios de salud: la falta de recursos humanos y materiales.

La segunda situación tiene que ver con la falta de conciencia en torno a los riesgos mineros y, por consiguiente, con la falta de capacitación, que parece no ser un elemento importante, ni para expertos ni para los legos. Es sabido que una vulnerabilidad educativa bien atendida conlleva aprendizajes para la anticipación de los riesgos tecnológicos. Por lo tanto, el hecho de que no se perciba que requiere atención, coloca a la región en una situación de mayor riesgo, que se ve (auto) reforzado por la vulnerabilidad técnica -como la baja capacidad de almacenamiento, la falta de impermeabilización de la presa de jales de la mina Buenavista del Cobre y la construcción de una nueva presa de jales a 30 kilómetros de Bacanuchi- y por la poca confianza institucional, producto de la falta de información e interacción de la minería con la comunidad.

Por último, cabe señalar que, siguiendo a Funtowicz y Ravetz (1993), en contextos de complejidad, hay un nuevo papel para la ciencia. Si bien ésta sigue siendo esencial e indispensable para la solución de los problemas medioambientales, por sí sola no resuelve los problemas propios de políticas complejas, bajo las cuales la simple acumulación de evidencia científica no asegura consensos en las soluciones (Gudynas, 2018). Como bien señala Beck (2015): “Sin racionalidad social, la racionalidad científica está vacía; sin racionalidad científica, la racionalidad social es ciega" (p. 44).

\section{Agradecimientos}

Las autoras agradecen el apoyo financiero al Fondo Ciencia Básica SEP-Conacyt y al proyecto Valoración del Impacto en el Desarrollo Económico de los Desastres Ambientales: el Derrame de Sulfato de Cobre en la Minería a Gran Escala en el Río Sonora (Ref. 257821).

\section{Referencias}

Albert, L., y Jacott, M. (2015). México tóxico. Emergencias químicas. México: Siglo XXI.

Alfie, M. (2015). Riesgo ambiental. La aportación de Ulrich Beck. Acta Sociológica (73), 171-194. doi: http://dx.doi.org/10.1016/j.acso.2017.08.006 
Beck, U. (2015). La sociedad del riesgo. Hacia una nueva modernidad. Barcelona: Paidós.

Blaikie, P., Cannon, I., Davis, I., y Wisner, B. (1996). Vulnerabilidad: el entorno social, político y económico de los desastres. Panamá: LaRed-Red de Estudios Sociales en Prevención de Desastres en América Latina.

Busso, G. (junio, 2001). Vulnerabilidad social: nociones e implicaciones de políticas para Latinoamérica a inicios del siglo XXI. Trabajo presentado en el Seminario Internacional. Las Diferentes Expresiones de la Vulnerabilidad social en América Latina y el Caribe, Santiago de Chile.

Cardona, D. (2001). La necesidad de repensar de manera holística los conceptos de vulnerabilidad y riesgo. Una crítica y una revisión necesaria para la gestión. Ponencia para Internacional Work-Conference on Vulnerability in Disaster Theory and Practice. Disaster Studies of Wegeningen University and Research Centre. Wegeningen, Holanda. Recuperado de https://www. desenredando.org/public/articulos/2001/repvuln/RepensarVulnerabilidadyRiesgo-1.0.0.pdf

Castrillón, C., Martínez, M., Puentes, M., Sánchez, R., y Tocancipa, J. (2015). Conocimiento local y riesgo por tsunami en Guapi, Cauca. Una perspectiva interdisciplinaria. Colombia: Universidad del Cauca. Recuperado de https://www.oceandocs.org/bitstream/handle/1834/14701/176_DIMAR.pd$\mathrm{f}$ ?sequence $=1$ \&isAllowed $=\mathrm{y}$

Celis, P. (1992). Diagnóstico de la contaminación del agua en el estado de Sonora. En José Luis Moreno (comp.), Ecología, recursos naturales y medio ambiente en Sonora (pp. 165-187). México: Gobierno del Estado de Sonora y El Colegio de Sonora.

Climent, A. I. (2002). Tercer mundo, desarrollo, desastre y tecnología. Miradas desde la Geografía. Serie Geográfica (10), 11-26. Recuperado de https:// dialnet.unirioja.es/servlet/articulo?codigo $=310087$

Douglas, M. (1996). La aceptabilidad del riesgo según las ciencias sociales. Barcelona: Paidós.

Douglas, M. , y Wildavsky, A. (1982). Risk and Culture. An Essay on the Selection of Technological and Environmental Dangers. Berkeley: University of California Press.

Ferrari, M. P. (2011). Percepción social del riesgo: problemáticas costeras y vulnerabilidades en playa Magagna (Chubut). Huellas (15), 13-33. Recuperado de http://www.biblioteca.unlpam.edu.ar/pubpdf/huellas/v15a03ferrari. pdf

Ferrari, M. P. (2017). Configuraciones del riesgo y percepción social: Los asentamientos La Lomita y Alta Tensión, Puerto Madryn, Chubut. Geograficando, 13(2), 1-16. Recuperado de https: / / ri.conicet.gov.ar/handle/11336/73453

Fordham, M. (2007). Gendering vulnerability analysis: towards a more nuanced approach. En Greg Bankoff, Georg Frerks y Dorothea Hilhorts (ed.), Mapping Vulnerability: Disasters, Development and People (pp. 174-182). Londres: Earthscan.

Foschiatti, A. M. H. (2007). Vulnerabilidad global: cuestiones de terminología. En A. M. H. Foschiatti (ed.), Aportes conceptuales y empíricos de la vulnerabilidad global (pp. 14-40). Resistencia, Chaco: EUDENE. 
Funtowicz, S. O., y Ravetz, J. R. (2000). La ciencia posnormal. Barcelona: Icaria.

Gálvez, C. (2015). Saberes locales en el mundo global. Huertas, agua y conocimiento agroecológico en la Alpujarra alta occidental (tesis de doctorado). Recuperado de https://rio.upo.es/xmlui/bitstream/handle/10433/2084/ galvez-garcia-tesis15.pdf?sequence=1\&isAllowed=y

García, V. (2005). El riesgo como construcción social y la construcción social de riesgos. Desacatos, 11-24. Recuperado de http: / /www.scielo.org.mx/scielo. php?pid=S1607-050X2005000300002\&script=sci_abstract

Gómez-Álvarez, A., Ortega-Romero, P. O., y Yocupicio-Anaya, M. T. D. J. (1990). Distribución de metales pesados en el río Sonora y su afluente el río Bacanuchi, Sonora, México. Revista Ecologica, 1(2), 10-20. Recuperado de https:// investigadores.unison.mx/ws/portalfiles/portal/6011351/Art_culo_R_o_Sonora_Ecologica_1990.pdf

Gudynas, E. (2018). Múltiples paradojas: ciencia, incertidumbre y riesgo en las políticas y gestión ambiental de los extractivismos. Polisemia, 14(25), 5-37. doi: 10.26620/uniminuto.polisemia.14.25.2018.1-33

Gutiérrez, N. (17 de diciembre de 2019). Lamentable doble discurso de Toledo, sobre situación en río Sonora. Infórmate.com.mx

Ibarra, M. F. , y Moreno, J. L. (2017). La justicia ambiental en el río Sonora. RevIISE, 10(10), 135-155. Recuperado de http://www.ojs.unsj.edu.ar/index. $\mathrm{php} /$ reviise/article/view/168

Instituto Nacional de Estadística y Geografía (INEGI). (2016a). Tabulados de la Encuesta Intercensal 2015. Recuperado de http://www.beta.inegi.org.mx/ programas/intercensal/2015/

Instituto Nacional de Estadística y Geografía (INEGI). (2016b). Marco geoestadístico. Recuperado de https://www.inegi.org.mx/app/biblioteca/ficha. html?upc $=702825217341$

Iturralde, R. S. (2014). La construcción social del riesgo y el conocimiento científico: un estudio de caso sobre un conflicto socioambiental en 30 de agosto, provincia de Buenos Aires. Cuadernos de Antropología (12), 175-189. Recuperado de https://ri.conicet.gov.ar/handle/11336/51223

Jhonson, B., y Covello, V. (1987). The social and cultural construction of risk: issues, methods and case studies. En V. Covello y B. Jhonson (eds.), The Social and Cultural Construction of Risk: Essays on Risk Selection and Perception. Dordrecht/Boston/Lancaster/Tokyo: D. Reidel Publishing Company.

López, J. A., y Luján, J. L. (2000). Ciencia y política del riesgo. Madrid: Alianza Editorial.

Lugo, C., y Lara, B. (2020). El conflicto socioambiental en el río Sonora. Análisis de la acción colectiva de las organizaciones de la sociedad civil de 2014 a 2018. Estudios Sociales, 30(55), 1-30. doi: https://dx.doi.org/10.24836/ es.v30i55.949

Luhmann, N. (1992). Sociología del riesgo. México: Universidad Iberoamericana.

Luque, D., Murphy, A., Jones, E., Búrquez, A., Martínez, A., Manrique, T., y Esquer, D. (2019). Río Sonora: el derrame de la Mina Buenavista del Cobre-Ca- 
nanea, 2014. Hermosillo: CIAD, Conacyt y Red Temática sobre el Patrimonio Biocultural. Recuperado de https://patrimoniobiocultural.com/archivos/ publicaciones/libros/Libro_electronico_PDF_Rio_Sonora.pdf

Martín, P. (1999). El sociograma como instrumento que desvela la complejidad. EMPIRIA. Revista de metodología en Ciencias Sociales (2), 129-151. Recuperado de http://revistas.uned.es/index.php/empiria/article/viewFile/713/642

Moreno, J. L. (1992). Probables impactos ambientales del tratado de libre comercio. En Autor (comp.), Ecología, recursos naturales y medio ambiente en Sonora (pp. 349-360). México: Gobierno del Estado de Sonora y El Colegio de Sonora.

Orozco, R., y Muhech, V. (2012). Anteproyecto del nuevo depósito para jales "Buenavista del Cobre" en Cananea, Sonora. Trabajo presentado en la XXVI Reunión Nacional de Mecánica de Suelos e Ingeniería Geotécnica, Cancún, México. Recuperado de https://www.smig.org.mx/admArticulos/eventos/1_Reunion_Cancun/2_XXVI_Reunion_Nacional/15_Geotecnia_ambiental_y_depositos_mineros/I140RSR_1.pdf

Ortega, J. J. (2014). Objetividad y valores en el análisis de riesgo tecnológico: una visión de las principales posturas. Tecnología \& Sociedad. Buenos Aires, 1(3), 11-41.

Otway, H., y Cohen, J. J. (1975). Revealed Preferences: Comments on the Starr Benefit-Risk Relationships. International Institute for Applied Systems Analysis Research Memorandum. Recuperado de https://www.semanticscholar. org/paper/Revealed-Preferences\%3A-Comments-on-the-Starr-Otway-Cohen/2415afde1b206506d789894d8b6b1780c4a330a1?p2df

Pinilla, J. P. (2012). Think tanks, saber experto y formación de agenda política en el Chile actual. Polis. Revista de la Universidad Bolivariana, 11(32), 119140. Recuperado de https://scielo.conicyt.cl/pdf/polis/v11n32/art08.pdf

Programa de Naciones Unidas para el Medio Ambiente (PNUMA). (2004). Apell para minería. Guía para la industria minera a fin de promover la concientización y preparación para emergencias a nivel local. Informe Técnico No. 41. México: PNUMA-ORPALC. Recuperado de http://www.unep.fr/shared/ publications/pdf/WEBx0057xPA-APELLminingES.pdf

Ruiz, J.C. (2005). De la construcción social del riesgo a la manifestación del desastre. Reflexiones en torno al imperio de la vulnerabilidad. Desacatos (19), 99-110. Recuperado de https:// www. redalyc.org/pdf/139/13901907.pdf

Sandoval, J. (2020). Vulnerabilidad-resiliencia ante el proceso de riesgo-desastre: un análisis desde la ecología política. Polis. Revista Latinoamericana (56), 138-154. doi: 10.32735/S0718-6568/2020-N56-1527

Secretaría de Economía (SE). (2015a). Listado de títulos de concesiones mineras. Última actualización publicada en Datos Abiertos de México [portal] del 2017-07-05, T00:00:00Z. México: SE. Recuperado de https://datos.gob.mx/ busca/dataset/listado-de-titulos-de-concesiones-mineras

Secretaría de Economía (SE). (2015b). Cartografía de concesiones mineras en el territorio nacional de SE, creado el 2015-10-27 17:37. Última actualización publicada en Datos Abiertos de México [portal] del 2018-03-13, T00:00:00Z. 
México: SE. Recuperado de https://datos.gob.mx/busca/dataset/cartografia-minera-de-se

Secretaría de Medio Ambiente y Recursos Naturales (SEMARNAT). (2015). Fideicomiso Río Sonora. México: SEMARNAT. Recuperado de https://www.gob. $\mathrm{mx} /$ semarnat/acciones-y-programas/fideicomiso-rio-sonora

Servicio Geológico Mexicano (SGM). (2018). Panorama minero del Estado de Sonora. México: SEG. Recuperado de http://www.sgm.gob.mx/pdfs/SONORA. pdf

Shrader-Frechette, K. S. (1991). Risk and rationality. Philosophical Foundations for Populist Reforms. Berkeley: University of California Press. Recuperado de https://publishing.cdlib.org/ucpressebooks/view?docld=ft3n39n8s1; query=; brand=ucpress

Sjöberg, L., y Drottz-Sjöberg, B. M. (1994). Risk perception of nuclear waste: experts and the public. Rhizikon Risk Research Report, 16. Stockholm: Center for Risk Research, Stockholm School of Economics.

Slovic, P. (2000). The Perception of Risk. Londres: Earthscan.

Soares, D., y Sandoval, N. C. (2016). Percepciones sobre vulnerabilidad frente al cambio climático en una comunidad rural de Yucatán. Tecnología y Ciencias del Agua, 7(4), 113-128.

Starr, C. (1969). Social benefit versus technological risk. Science (165), $1232-$ 1238. doi: 10.1126/science.165.3899.1232

Toscana, A., y Hernández, P. (2017). Gestión de riesgos y desastres socioambientales. El caso de la mina Buenavista del Cobre de Cananea. Investigaciones Geográficas (93), 2-14. doi: dx.doi.org/10.14350/rig.54770

Urra, E., Muñoz, A. , y Peña, J. (2013). El análisis de discurso como perspectiva metodológica para investigadores de salud. Enfermería Universitaria, 10(2), 50-57.

Vallejos-Romero, A. , y Garrido, J. (2019). Las narrativas del riesgo en la Patagonia chilena. Perfiles Latinoamericanos, 27(53), 1-23. doi: 10.18504/pl2753015-2019

Vega, L., Cirett, S., Parra, M. L. de la, y Zavala, R. (2011). Hidrogeología de Sonora, México. En T. Calmus (ed.), Panorama de la geología de Sonora (pp. 267-298). México: Universidad Nacional Autónoma de México. Instituto de Geología. Recuperado de http://www.geologia.unam.mx:8080/igl/publs/ boletin/bol118/(8)Vega.pdf

Wilches-Chaux, G. (1993). La vulnerabilidad global. En A. Maskrey (ed.), Los desastres no son naturales (pp. 11-41). Perú: La Red. Recuperado de https:// www.desenredando.org/public/libros/1993/ldnsn/LosDesastresNoSonNaturales-1.0.0.pdf

Wilches-Chaux, G. (1998). Auge, caída y levantada de Felipe Pinillo, mecánico o soldador o Yo voy a correr el riesgo. Perú: La Red. Recuperado de https: / / www.desenredando.org/public/libros/1998/gglr/GGLR_todo_ene-7-2003. pdf 